\title{
Employment of Set Operations to Improve LMP Assessments Design and Implementation
}

\author{
Malek Khalaf Albzeirat ${ }^{1}$
}

Rosmaini Ahmad

Muhammad Iqbal Hussain

Falah Mustafa Al-Saraireh

Asia Khalaf Albzeirat

Received 2018-11-30

Accepted 2018-12-27

Published 2019-01-01

Keywords

Lean Manufacturing Practices,

Waste Management,

Lean Assessment

Set Operations

\section{How to cite?}

Alberuirat, M., Ahmad, R., Hussain, M., Al-Saraireh, F., \& Albzeirat, A. (2019). Employment of Set Operations to Improve LMP Assessments Design and Implementation. SEISENSE Journal of Management, 2(1), 33-46. bttps:/ / doi.org/10.33215/sjom.v2i1.56

Copyright (c) 2019 The Author(s)

\section{(cc) BY}

School of Manufacturing Engineering, Universiti Malaysia Perlis, Kampus Alam Pauh Putra, 02600 Arau, Perlis Malaysia

School of Manufacturing Engineering, Universiti Malaysia Perlis, Kampus Alam Pauh Putra, 02600 Arau, Perlis Malaysia

School of Manufacturing Engineering, Universiti Malaysia Perlis, Kampus Alam Pauh Putra, 02600 Arau, Perlis Malaysia

Department of Mechanical Engineering, Mutah University, Mutah, Alkarak, Jordan

Department of Math, Mutah University, Mutah, Alkarak, Jordan

\begin{abstract}
Objective - This paper aims to provide a new mathematical model for the construction of assessment tools for Lean Manufacturing Practices (LMP) through the integration process with the set operations. This study also strives to develop key elements to enhance the effectiveness of LMP assessments and their impact through mathematical interrelationship. Problem - Previous studies have shown a lack of clear mathematical methodology to carry out a rigorous assessment of the LMP effects on the firm's operational and financial performance. Therefore, this paper tries to address this aspect by developing new equations. Design - The methodology of this study is based on the conversion of the linguistic description (companies, processes, waste, practices) into numerical measurement model by integrating with set theory. Finding - The results show a set of relationships and equations that can be applied to be a fundamental basis for ensuring the effectiveness of the assessment. This paper may contribute to the improvement of LMP's design and development.
\end{abstract}

${ }^{1}$ Corresponding author's email address: eng.malekkhalaf@gmail.com 


\section{Introduction}

According to many studies, the practice of lean manufacturing has been used to effectively improve the operational and financial performance of the organization (Taj and Morosan, 2011; Dora et al., 2013; Fullerton et al., 2014; Godinho Filh et al., 2016; Negrão et al., 2017). The lean can be defined according to a common formula for what has been described in previous studies (Alhuraish et al., 2017; Tagge et al., 2017; Laureani and Antony, 2017; Randhawa and Ahuja, 2017) as a work without waste that includes a set of practices, thereby contributing to improved performance in the organizations. On the other hand, waste can be defined as anything that has no value within the institution, such as anything other than the minimum amount of equipment, materials, parts, and working time that are essential to production (Pavnaskar et al, 2003; Taj, 2008; Taj, 2011; chen et al., 2013). Common waste in the enterprises includes seven types, namely Transportation, Inventory, Motion, Waiting, Overproduction, Over processing and Defects (Arunagiri Gnanavelbabu, 2014; Qureshi et al, 2015). The elimination of previous waste through lean practices helps to reduce the enterprises excessive spending and over-effort (Siasos et al., 2017). In order to measure these positive effects of the lean practices on performance, there are many studies in the field of evaluation, and most of these studies have followed the descriptive logic of the relationship between performance and lean applications. Most of the results show the depth of the relationship between performance and lean practices (Negrão et al., 2017). However, despite these references, especially in quantitative and quantitative studies there is a lack of actual value of its effect. The previous studies are based on providing descriptive result of the relationship only. Therefore, this issue is considered as the focus of the present study for mathematical models and the development of mathematical models to achieve a methodology that provides a numerical description of the relation between lean and operational and financial performance to make the evaluation process more effective. Over the past decade, 130 studies were conducted at different institutions in the world in the field of LMP Assessment. By analyzing the methodology used in these studies, it was found that they adopted quantitative and qualitative methodologies without focusing on the mathematical logic in explaining the results of measurement. Figures 1-2 shows the distribution of the assessment methodology between (quantity, type, integration of quantity and type, other methods, Mathematical Model), and these differences show no general logic of measurement.

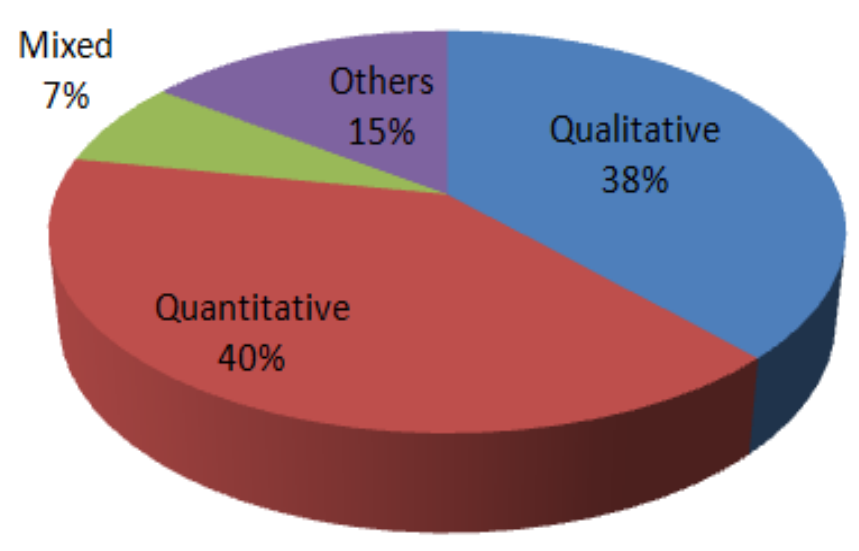

Figure 1 - Relative Distribution of Methodology 


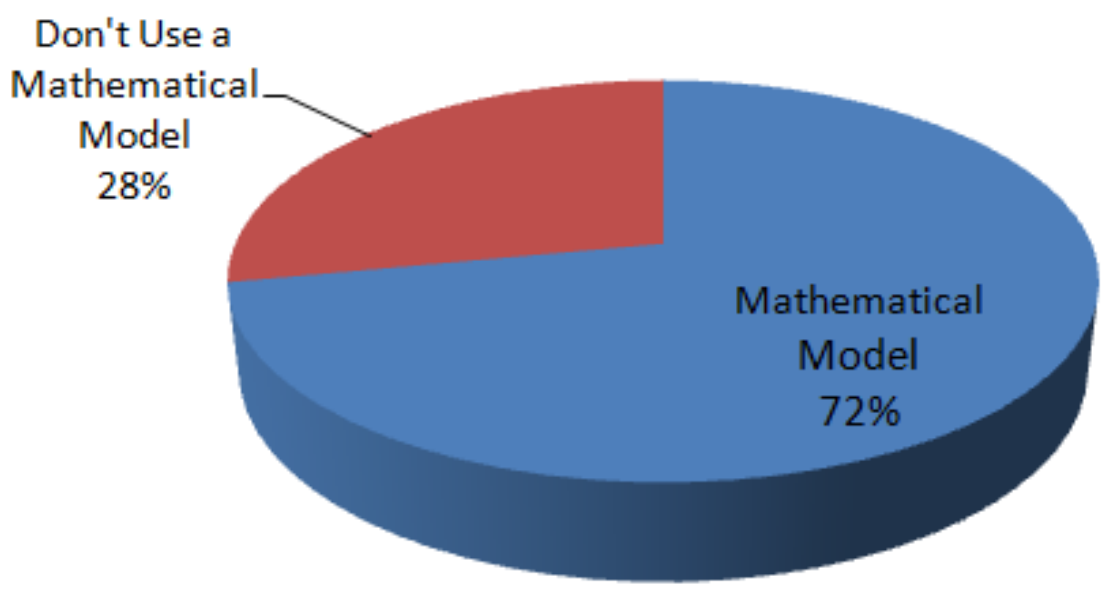

Figure 2 - Relative Distribution of Use Mathematical Model or Not Use

Some studies have made references to the development of a digital concepts that indicate the effects of practices in the performance through mathematical models that provides different weights but are not comprehensive (Cil et al., 2013). Some other studies have also attempted a digital measurement of the performance through the use of Analytic Hierarchy Thanki et al., 2016; Alhuraish et al., 2017). Therefore, this study will extend the digital description in evaluating the impact of lean on the performance, thus updating what has been achieved in this field (Albzeirat et al., 2018). The structure of this study will include the Introduction, which provides a preliminary conception of the objectives of the study and the elements of the study in general, followed by the second section, which includes the methodology of the study. The fourth section includes the integration of the basic elements of the study (companies, operations, waste. Finally, the conclusions are discussed in the fifth section.

\section{Method}

This study aims to develop the mathematical equations that can give a new perception of the descriptive state of the relationship between LMP, companies, processes, waste and performance. It is known that the engineering application transcends administrative and descriptive science by giving a digital representation of data and relationships. In this context, the description of the relationship between LMP and performance will be exceeded by mathematical equations that reflect a more accurate perception of this relationship. To achieve this goal, this study will include Figure 3.

The methodology will be achieved through the following steps:

First: Defining LMP in general and establishing the mathematical representation of the general set of lean practices based on set operations.

Second: Identifying the general groups of the classification of institutions according to the type of companies and the status of the mathematical representation of these groups based on set operations.

Third: Determining the total waste that can be formed in these companies based on set operations.

Fourth: Identifying the group of practices that represent a solution for the removal of waste in each group of types of waste type according to the type of company based on set operations. 
Fifth: Conversion of representation in previous collections to mathematical equations based on set operations.

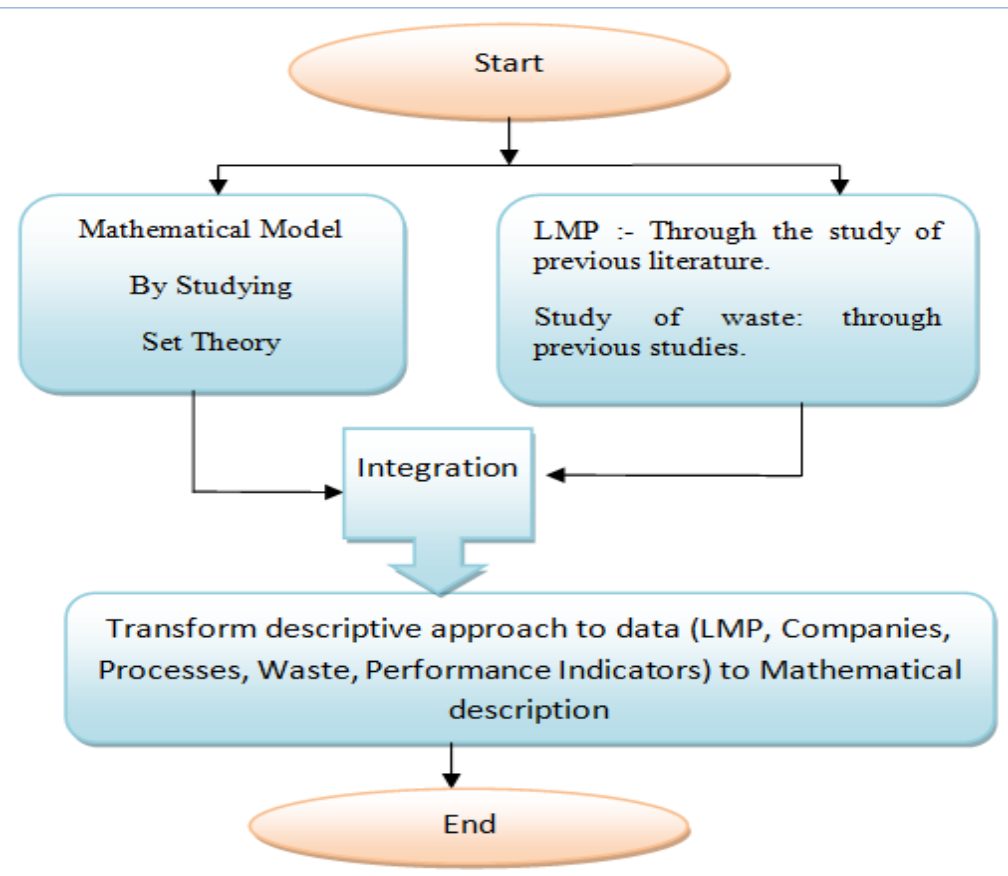

Figure 3 - Overview Work Flow for Research Methodology

\section{General Lean Manufacturing Set}

This part of the study defines lean manufacturing practices in general and establishes the mathematical representation of the general set of lean practices. Therefore, the mathematical representation of the meaning of the set is called and applied to obtain the mathematical form of the general set of lean manufacturing practices (GSLMP) by using a mathematical application that includes a set logic known as a group theory. Based on review of the previous studies, it is clear that the LMP represents a set of practices that aim at making a positive change in the company or plant performance. As an illustration, GSLMP can be mathematically defined as follows:

\section{Definition 1.}

$$
\begin{aligned}
& \text { GSLMP } \\
& =\left\{L_{i}^{M P} \mid L_{i}^{M P} \quad \mathrm{i}=\{1, \ldots, n\} \text { where } \mathrm{n} \text { is a Number of } \mathrm{LMP}\right\} \\
& =\left\{L_{1}^{M P}, L_{2}^{M P}, \ldots, L_{n}^{M P}\right\},
\end{aligned}
$$

Where $L_{i}^{M P}$ Symbolizes one practice that belongs to this set, in mathematical sense $L_{i}^{M P} \in$ GSLMP and $i \in\{1,2, \ldots, \mathrm{n}\}$.

By means of the Set Theory characteristics, subsets can be formed within specific classifications of a set, which can be formed by a set containing at least one element of the GSLMP elements. Mathematically, SSLMP can be represented as a subset of GSLMP. All the elements in SSLMP are contained or members of the large set GSLMP, where the notation SSLMP $\subseteq$ SGLMP to indicate SSLMP a subset of the set GSLMP. In 
other words, SSLMP $=\left\{L_{d}^{M P} \mid L_{d}^{M P} d \subseteq\{1, \ldots, n\}\right\}$, the SSLMP can be defined as a set that includes a set of LMP related to:

- Companies type

- Waste type

- Particular process

From this point of view, practices can be classified according to processes, waste, and types of companies. Each of the previous categories can be represented by sets, as follows:

- Set of Companies (SC).

- Set of Waste (SW).

- Set of Processes (SP).

These sets can be expressed mathematically through a group theory as follows:

\section{Definition 2.}

Set of Waste (SW): $\{W \mid W \quad W \in S W\}=\{T, I, W, M, O P S, O P, D\}$.

Also SW can be represented as follows:

$$
\begin{gathered}
\text { If } T=W_{1}, I=W_{2}, W=W_{3}, M=W_{4}, O P S=W_{5}, O P=W_{6} \text { and } D=W_{7} \text { then } \\
\qquad \bigcup_{i=1}^{7} W_{i}=W S .
\end{gathered}
$$

\section{Definition 3.}

Set of Companies (SC): $\{C \mid C C \in$ Companies $\}=\left\{C_{1}, \ldots, C_{m}\right\}$, whereby $m$ is a number of a Company. Also C can be represented as:

$$
C=\bigcup_{i=1}^{m} C_{i}
$$

\section{Definition 4.}

Set of Processes (SP): $\{P \mid P P \in$ Pocesses $\}=\left\{P_{1}, \ldots, P_{z}\right\}$, whereby $z$ is a number of processes. Also SP can be represented by:

$$
S P=\bigcup_{i=1}^{z} P_{i}
$$

Through the descriptive and practical relationships between LMPand Definitions 3-.5, the following descriptive theories can be inferred:

Theory 1. From the logic of a difference in the types of waste, there is a difference in the type of appropriate LMP for each type of waste. It is therefore a mathematical logic to have a subset of LMP suitable for each type of waste. 
The relationship between Equations 1 and 2 in Theory 1 can be represented as follows:

$$
\text { If } W_{i} \in S W \Rightarrow \exists \operatorname{SSLMP}_{w_{i}} \subseteq \mathrm{GSLMP}
$$

Where the $L_{q}^{M P} \in \mathrm{SSLMP}_{w_{i}}, q \in\{1, \ldots n\}, \mathrm{i} \in\{1, \ldots, 7\}$ contributes to the removal and disposal at least part of waste $\operatorname{in} W_{i}$.

Theory 2. From the logic of a difference in the types of companies, there is a difference in the type of appropriate LMP for each type of waste in companies. It is therefore a mathematical logic to have a subset of LMP suitable for each type of company. The relationship between Equations 1 and 3 in Theory .2 can be represented as follows:

$$
\text { If } C_{i} \in C \Rightarrow \exists \operatorname{SSLMP}_{C_{i}} \subseteq \text { GSLMP. }
$$

Where the $L_{q}^{M P} \in \operatorname{SSLMP}_{C_{i}}, q \in\{1, \ldots n\}, \mathrm{i} \in\{1, \ldots, \mathrm{m}\}$ can be applied in this type of companies.

Theory 3. From the logic of a difference in the types of processes, there is a difference in the type of appropriate LMP for each type of processes. It is therefore a mathematical logic to have a subset of LMP suitable for each type of processes.

The relationship between Equations 1 and 4 in theory 3 can be represented as follows:

$$
\text { If } P_{i} \in S P \Rightarrow \exists \operatorname{SSLMP}_{P_{i}} \subseteq \mathrm{GSLMP}
$$

Where the $L_{q}^{M P} \in \operatorname{SSLMP}_{P_{i}}, q \in\{1, \ldots n\}, \mathrm{i} \in\{1, \ldots, z\}$ can be applied in this type of companies.

The previous definitions include the following aspects:

1. Classification of practices depending on the type of companies.

2. Classification of practices by the type of operation.

3. Classification of practices according to the type of waste.

\section{Combining Waste with Companies}

Different types of companies, industrial, service, logistics, educational, health... etc. This difference in the classification of companies gives a difference in the type of waste, depending on the classification of the company, and this logic can be represented by:

CSS: a group of companies that includes a joint description, such as energy companies, mining, education, health ...etc. Each of these Subsets may include a variety of waste types. The SSC can be represented through the Set Theory as follows:

Through the Set Theory characteristics, subsets can be formed within specific classifications of a set, which can be formed by a set containing at least one element of the elements of SC.

This requires a description of the classification; namely a system to classify companies and enterprises according to the activities in which they are engaged.

Through the characteristics of groups, the following relationships can be inferred:

$$
S C=\left\{s_{1} S C, s_{2} S C, \ldots, s, s C\right\} .
$$

Whereby $S_{t} S C$ contains a subset of companies and $t \in\{1, \ldots, r\}$. 


$$
\begin{aligned}
& S_{y} S C \cap S_{u} S C=\varnothing, \text { where } y \text { and } u \in\{1, \ldots, r\}, \\
& \bigcup_{i=1}^{r} S_{i} S C=S C
\end{aligned}
$$

Through the integration between the waste and companies classification by combining relations 2,3 and 8 , the following sets are formed:

$$
\begin{aligned}
& W S_{i} S C \text { Waste of } S_{i} S C, \text { where } i \in\{1, \ldots, r\} \\
& W S_{i} S C \subseteq S W . \\
& \bigcup_{i=1}^{N} W S_{i} S C \subseteq W S, \text { Where } N \leq r .
\end{aligned}
$$

To identify a set of waste in any group of companies, the following steps are taken:

1. Identifying processes.

2. Monitoring processes through the observation and digital values.

3. Designing an appropriate assessment to determine the presence of waste.

\section{Combining Processes with Company}

Each process has its own conditions that may include the human factor, the technical and the machinery. These diversity factors are shown in the diversity of wastes and the differences according to the tasks in the process. Consequently, each process involves a group of waste, whereby this group can be expressed through Group Theory as follows:

Set of Processes for company (SPC) by combining relations 3, 4 and 8:

$$
\begin{aligned}
& S P C_{i}=\left\{P_{1} C_{i}, \ldots, P_{m} C_{i}\right\} \\
& S P C_{i}=\left.\left[P C_{i}\right]\right|_{m \times 1}=\bigcup_{n=1}^{m} P_{n} C_{i}
\end{aligned}
$$

It can be represented in the form of a matrix as follows:

Matrix of processes for company:- $S P C_{i}=\left[\begin{array}{l}P_{1} C_{i} \\ P_{2} C_{i} \\ \cdot \\ \cdot \\ \cdot \\ - \\ P_{m-1} C_{i} \\ P_{m} C_{i}\end{array}\right]$

Set of Processes for Set of Companies (SPSC) as:

$$
\begin{aligned}
S P S C & =\left.[P]\right|_{Z \times 1} \times\left.[C]\right|_{1 \times m} \\
S P S C & =\left[P_{z} C_{m}, z \text { Number of Proceeses and } m \text { Number of Companies }\right] \\
& =\left\{P_{1} C_{1}, \ldots, P_{z-1} C_{1}, P_{z} C_{1}, P_{2} C_{1}, \ldots, P_{z-1} C_{2}, P_{z} C_{2}, \ldots, P_{z-1} C_{m}, P_{z} C_{m}\right\}
\end{aligned}
$$

It can be represented in the form of a matrix as follows: 
Set of Processes for a Subset of Companies (SPSSC):

$$
S P S S C=\left\{S P S_{1} S C, \ldots ., S P S_{v} S C, \text { where } v \text { Number of Subset of Companies }\right\}=\bigcup_{i=1}^{v} P S_{i} S C
$$

by relations 4 and 8 . It can be represented in the form of a matrix as follows:

$$
\begin{aligned}
& S P S C=\left(\begin{array}{cccccc}
\overbrace{P_{1} C_{1}}^{S P S_{1} S C} & \ldots & \ldots & \ldots & \ldots & P_{1} C_{m} \\
\vdots & \ddots & \vdots & \ldots \ldots \ldots & \ddots & \vdots \\
P_{z} C_{1} & \ldots & \ldots & \ldots & \cdots & P_{z} C_{m}
\end{array}\right), r<m \\
& S P S C=\left(\begin{array}{ccc}
S P C_{1} & & S P C_{m} \\
P_{1} C_{1} & \cdots & P_{1} C_{m} \\
\vdots & \ddots & \vdots \\
P_{z} C_{1} & \cdots & P_{z} C_{m}
\end{array}\right)
\end{aligned}
$$

In order to achieve the accuracy of the assessment tool, the classification of waste is determined according to the processes within the company. This classification can be obtained through the matrix of the integration of processes and waste, and can be represented as follows:

Set Waste of Processes for company (SWPC) by relations 2 and 14:

$$
S W P C_{i}=\left\{W P_{1} C_{i}, \ldots . ., W P_{m} C_{i}\right\}, S W P C_{i}=\bigcup_{n=1}^{m} S W P_{n} C_{i}
$$

It can be represented in the form of a matrix as follows:

$$
S W P C_{i}=\left[S P C_{i}\right]_{m \times 1} \times[T, I, W, M, O P S, O P, D]_{1 \times 7}
$$

$$
\begin{aligned}
& S W P C_{i}= {\left[\begin{array}{ccccccc}
W_{1} P_{1} C_{i} & W_{2} P_{1} C_{i} & W_{3} P_{1} C_{i} & W_{4} P_{1} C_{i} & W_{5} P_{1} C_{i} & W_{6} P_{1} C_{i} & W_{7} P_{1} C_{i} \\
\cdot & \cdot & \cdot & \cdot & \cdot & \cdot & \cdot \\
\cdot & \cdot & \cdot & \cdot & \cdot & \cdot & \cdot \\
\cdot & \cdot & \cdot & \cdot & \cdot & \cdot & \cdot \\
\cdot & \cdot & \cdot & \cdot & \cdot & \cdot & \cdot \\
W_{1} P_{m} C_{i} & W_{2} P_{m} C_{i} & W_{3} P_{m} C_{i} & W_{4} P_{m} C_{i} & W_{5} P_{m} C_{i} & W_{6} P_{m} C_{i} & W_{7} P_{m} C_{i}
\end{array}\right] } \\
& \text { As a set } S W P C_{i}=\{\overbrace{W_{1} P_{1} C_{i}, \ldots, W_{7} P_{1} C_{i}}^{S W \ldots, W_{1} P_{m} C_{i}, \ldots, W_{7} P_{m} C_{i}}\} .
\end{aligned}
$$

\section{Combining Waste with Processes and Lean Manufacturing Practices}

Different processes and waste variation indicate the difference in the lean practices that can be used to remove wastes in each process. Based on this logic, practices can be classified according to the type of processes. To determine the relationship between practices and waste, the mathematical model must be developed to represent this relationship through the Group Theory as follows:

Relations 1 and 18 Set of Lean Manufacturing Practices for Process in company (SLMPPC) given by: 


$$
\begin{aligned}
& \operatorname{SLMPPC}_{i}=[G S L M P]^{T} \times\left[S W P C_{i}\right] \\
& =\left[L_{1}^{M P}, L_{2}^{M P}, \ldots, L_{n}^{M P}\right]_{1 \times n}^{T} \times[\overbrace{W_{1} P_{1} C_{i}, \ldots, W_{7} P_{1} C_{i}}^{S W P_{1} C_{i}}, \ldots, \overbrace{W_{1} P_{m} C_{i}, \ldots, W_{7} P_{m} C_{i}}^{s W P_{m} C_{i}}]_{1 \times 7} \\
& S L M P P C_{i}=\left[\begin{array}{c}
L_{1}^{M P} \\
\cdot \\
\cdot \\
\cdot \\
\cdot \\
L_{n}^{M P}
\end{array}\right]_{n \times 1} \overbrace{W_{1} P_{1} C_{i}, \ldots, W_{7} P_{1} C_{i}}^{S W P_{1} C_{i}}, \ldots, \overbrace{W_{1} P_{m} C_{i}, \ldots, W_{7} P_{z} C_{i}}^{S W P_{m} C_{i}}]_{1 \times m}
\end{aligned}
$$

From the previous general matrix, the appropriate practices for each particular process can be identified as follows:

$$
\operatorname{LMPP}_{s} C_{i}=\left[\begin{array}{c}
L_{1}^{M P} \\
\cdot \\
\cdot \\
\cdot \\
L_{n}^{M P}
\end{array}\right]_{n \times 1} \times[\overbrace{W_{1} P_{s} C_{i}, \ldots, W_{7} P_{s} C_{i}}^{S W P_{P} C_{i}}]_{1 \times 7}
$$

Where, $\operatorname{LMPP}_{s} C_{i} \subseteq S L M P P C_{i}, s \in\{1, \ldots . m\} . s \in\{1, \ldots, m\}$,

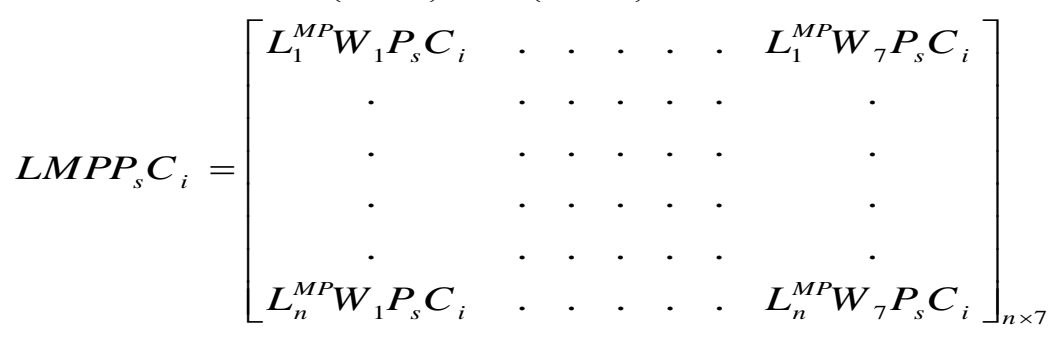

Through the previous matrix " ", the following sets can be found:

1. Set of Lean Manufacturing Practices for Transportation Waste Related the Processes s in Company I:

$$
S L^{M P} W_{1} P_{s} C_{i}=\bigcup_{v=1}^{n} S L_{v}^{n} W_{1} P_{s} C_{i}
$$

2. Set of Lean Manufacturing Practices for Inventory Waste Related the Processes s in Company I:

$$
S L^{M P} W_{2} P_{s} C_{i}=\bigcup_{v=1}^{n} S L_{v}^{n} W_{2} P_{s} C_{i}
$$

3. Set of Lean Manufacturing Practices for Waiting Waste Related the Processes s in Company W:

$$
S L^{M P} W_{3} P_{s} C_{i}=\bigcup_{v=1}^{n} S L_{v}^{n} W_{3} P_{s} C_{i}
$$

4. Set of Lean Manufacturing Practices for Motion Waste Related the Processes s in Company M:

$$
S L^{M P} W_{4} P_{s} C_{i}=\bigcup_{v=1}^{n} S L_{v}^{n} W_{4} P_{s} C_{i}
$$


5. Set of Lean Manufacturing Practices for Over Processes Waste Related the Processes s in

$$
\text { Company OPs: } S L^{M P} W_{5} P_{s} C_{i}=\bigcup_{v=1}^{n} S L_{v}^{n} W_{5} P_{s} C_{i}
$$

6. Set of Lean Manufacturing Practices for Over Production Waste Related the Processes s in

$$
\text { Company OP: } S L^{M P} W_{6} P_{s} C_{i}=\bigcup_{v=1}^{n} S L_{v}^{n} W_{6} P_{s} C_{i}
$$

7. Set of Lean Manufacturing Practices for Defect Waste Related the Processes s in Company i:

$$
S L^{M P} W_{7} P_{s} C_{i}=\bigcup_{v=1}^{n} S L_{v}^{n} W_{7} P_{s} C_{i}
$$

8. Based on the above, the total set can be determined to remove all wastes in the process in the company i that can be given by:

$$
L M P P_{s} C_{i}=\bigcup_{v=1}^{n} \bigcup_{\forall r \in\{1, \ldots, 7\}} S L_{v}^{n} W_{r} P_{s} C_{i}
$$

9. Based on the above, the total set can be determined to remove all wastes in all the processes in the company i which can be given by:-

$$
L M P P_{s} C_{i}=\bigcup_{v=1} \bigcup_{r \in\{1, \ldots, 7\} \text { and } s \in\{1, \ldots m\}}^{n} S L_{v}^{n} W_{r} P_{s} C_{i}
$$

10. It is known that practices may target the human behavior and may be within the framework of a machinery. Hence, this practice can be divided into two sets:

$$
\begin{aligned}
& \text { Human Practices: } H L^{M P}=\left\{H L_{1}^{M P}, \ldots, H L_{h}^{M P}\right\}, h<n . \\
& \text { Technical Practices: } T L^{M P}=\left\{T L_{1}^{M P}, \ldots, T L_{t}^{M P}\right\}, t<n . \\
& \bigcup_{i=1}^{h} H L_{i}^{M P} \cup \bigcup_{i=1}^{t} T L_{i}^{M P}=G S L M P . \\
& t+h=n .
\end{aligned}
$$

Depending on the characteristics of the intersection, union and the characteristics of operations, the sets of practices include the following possibilities:

1. Sets can intersect with each other.

2. The output of the intersection may be an empty set $\varnothing$.

3. Each set of practices in any process is a subset of the total set of practices.

4. Each practice includes a certain impact rate on waste.

\section{Mathematical Equations and Financial Values}

To demonstrate the effectiveness of the previous logic, the former mathematical logic in sections 3.1-3.4 must be converted to mathematical values, which can be reviewed as follows:

\section{Capacity of Production for Companies}

Each company has a capacity Production "Quantity" where the percentage of the amount of production can be calculated by means of this quantity. These values vary relatively from one company to another, and therefore, these values can take multiple ratios for the total amount of actual production. Accordingly, it is possible to derive the following relationships:

The Productivity Quantity of Company $i=\delta_{c_{i}}, i \in\{1, \ldots m\}$.

Total Quantity Production of all Companies $=\delta_{s c}$. 


$$
\sum_{i=1}^{m} \delta_{c_{i}}=\delta_{s c}
$$

The Total Percentage of Amount of Capacity Productions of All Companies

$$
T P A P_{s c}=\sum_{i=1}^{m} P A P_{c_{i}}=100 \%
$$

Where $P A P_{c_{i}}=\frac{\delta_{c_{i}}}{\delta}$ and Symbolizes to the percentage of amount of production for company i.

\section{Amount of Production of Processes}

Each process has a Production Capacity of Operations in the company. These values vary relatively from one process to another, and therefore, these values can take multiple ratios for the total actual value of production in the company. Accordingly, it is possible to derive the following relationships:

Every process in the company $i$ has a productivity value $\delta_{P_{i} C_{i}}$, where $t \in\{1, \ldots, z\}$ and $i \in\{1, \ldots m\}$.

$$
\delta_{P_{i} C_{i}}=\sum_{t=1}^{z}\left(\delta_{c_{i}} \times W P_{t}\right)
$$

Where $W P_{t}$ Symbolizes the weight of processes, where $\sum_{t=1}^{z} W P_{t}=1$ and $\sum_{t=1}^{z} \delta_{P_{t} C_{i}}=\delta_{c_{i}}$.

\section{Actual Performance of Companies}

It is known that each company has a real performance value, and this value shows the actual value of production compared to the available human or technical capabilities. Through the indicators of production, performance of companies can determine the actual values that can be achieved by the improvement, and through the actual performance, values can be formulated by the following equations:

The true value of the optimum performance of all companies $\left(O P_{S C}\right)$ representing a percentage of $100 \%$, which is evident through the following equation:

$$
O P_{S C}=\sum_{i}^{m} O P_{C_{i}}=100 \% \text {. }
$$

The percentage of the performance defect for company i $\left(P D P_{c_{i}}\right)$ can be given through the following relationship:

$$
\begin{gathered}
P D P_{c_{i}}=O P_{C_{i}}-\text { The Current Performance } \\
=100 \% \text {-The Current Performance. }
\end{gathered}
$$

The percentage of performance defect for company i $\left({ }^{P D P_{c_{i}}}\right)$ as part of the imperfections of the performance of all companies can be given through the following relationship:

$$
P D P_{C_{i}}=\frac{D P_{C_{i}} \times W_{C_{i}}}{\sum_{i=1}^{m} D P_{S C}=\sum\left(D P_{C_{i}} \times W_{C_{i}}\right)},
$$

Where $W_{C_{i}}$ Symbolizes the weight of company i.

$D P_{c_{i}}$ Consists of a set of defects in the performance of processes $\left(S D P_{P C_{i}}\right)$. Accordingly, the following relationship can be constructed: 


$$
S D P_{C_{i}}=\left\{D P_{C_{1}}, \ldots D P_{C_{z}}\right\} .
$$

The Financial Value of the Waste in Company i $\left(F V W_{c_{i}}\right)$ ) can be obtained through the following relationship:

$$
F V W_{C_{i}}=F V P_{c_{i}} \times P D_{C_{i}}
$$

Where $F V P_{C_{i}}$ Symbolizes the Financial value of production.

\section{Waste and Performance}

It is logical to have a defect in the performance due to the presence of waste in the process. Through this relationship, the financial value of waste (FVW) is given through the reflection in the financial value of the defect in the processes. Consequently, the defect related to any process is a measure of the existence of waste and can be represented in the following relationship:

$\mathrm{FVW}$ in company $\mathrm{i}\left(F V W C_{i}\right)$ is given by:

$$
F V W_{C_{i}}=\sum_{t=1}^{z} F V D_{P_{i} C_{i}}=F V D_{C_{i}}
$$

These wastes may be related to human or technical factors, all of which lead to a poor performance for real values. AS a result, the Equation 4.44 can be rewritten as follows:

$$
F V W_{C_{i}}=F V H W_{C_{i}}+F V T W_{C_{i}}=\sum_{t=1}^{z} F V D_{P_{t} C_{i}}=F V D_{C_{i}} .
$$

\section{Actual Values of Impact LMP}

LMP is used to remove waste, and due to the different processes and wastes, there is a difference in the impact of the use of LMP on the performance. The relationship between practices and performance varies according to the set of practices that can be applied to waste elimination. Based on this logic, practices can be arranged within the reflections of financial values that ensure prioritization in the application of LMPs to ensure real returns to their application. These values can contribute to the development of effective programs in determining practices and the mechanism of their application. Accordingly, actual values of the impact LMP (AVILMP) applications for performance improvement should be close to the value of loss in performance. It can be mathematically expressed by:

$$
A V I L M P S \approx F V D_{C_{i}} .
$$

The value of use and application LMP should not exceed the value of loss in performance.

\section{Make Decision to Apply LMP}

The decision to apply LMP must be based on an actual value that ensures the achievement of positive results, and through the values of the previous equations, a set of steps can be taken to make the appropriate decision as follows: 
1. Determining the actual value of the performance of the company.

2. Determining the actual value of the resulting performance improvement.

3. Determining the actual value of each process in the performance.

4. Determining the actual value of impact wastes on the performance.

5. Determining the financial value of the application LMPs.

6. Quantitative comparisons between the cost of application of practices and expected results.

7. Making decision.

\section{Conclusions}

In summary, this study presents a new methodology to assess the effect of LMP on the performance in enterprises. Through the use of the methodology, reliable mathematical equations are used to measure the effect of LMP directly on the financial performance and the operational performance of the enterprises. These results will be more effective than the description language approach to the relationship between LMP and performance. The process of developing this new methodology is based on the integration between the Set Theory and management, which can be a strong basis for further development in the design of evaluation tools in further research in the future.

\section{Conflicts of Interest}

The authors declare no conflicts of interest.

\section{References}

Albzeirat, M. K., Hussain, M. I., Ahmad, R., Al-Saraireh, F. M., \& Ahmad, I. (2018). A Novel Mathematical Logic for Improvement Using Lean Manufacturing Practices. Journal of Advanced Manufacturing Systems, 17(03), 391-413. Doi: 10.1142/S0219686718500233.

Alefari, M., Salonitis, K., \& Xu, Y. (2017). The role of leadership in implementing lean manufacturing. Procedia CIRP, 63, 756-761. Doi: 10.1016/j.procir.2017.03.169.

Alhuraish, I., Robledo, C., \& Kobi, A. (2017). A comparative exploration of lean manufacturing and six sigma in terms of their critical success factors. Journal of cleaner production, 164, 325-337. Doi: 10.1016/j.jclepro.2017.06.146.

Alhuraish, I., Robledo, C., \& Kobi, A. (2017). A comparative exploration of lean manufacturing and six sigma in terms of their critical success factors. Journal of cleaner production, 164, 325-337. Doi: 10.1016/j.ifacol.2016.07.550.

Arunagiri, P., \& Gnanavelbabu, A. (2014). Identification of major lean production waste in automobile industries using weighted average method. Procedia Engineering, 97, 2167-2175.

Chen, J. C., Cheng, C. H., \& Huang, P. B. (2013). Supply chain management with lean production and RFID application: A case study. Expert Systems with Applications, 40(9), 3389-3397. Doi: 10.1016/j.eswa.2012.12.047.

Cil, I., \& Turkan, Y. S. (2013). An ANP-based assessment model for lean enterprise transformation. The International Journal of Advanced Manufacturing Technology,64(5-8), 1113-1130. Doi : 10.1007/s00170-012-4047-x.

Dora, M., Kumar, M., Van Goubergen, D., Molnar, A., \& Gellynck, X. (2013). Operational performance and critical success factors of lean manufacturing in European food processing SMEs. Trends in Food Science \& Technology, 31(2), 156-164. Doi: 10.1016/j.tifs.2013.03.002. 
Fullerton, R. R., Kennedy, F. A., \& Widener, S. K. (2014). Lean manufacturing and firm performance: The incremental contribution of lean management accounting practices. Journal of Operations Management, 32(7-8), 414-428.

Godinho Filho, M., Ganga, G. M. D., \& Gunasekaran, A. (2016). Lean manufacturing in Brazilian small and medium enterprises: implementation and effect on performance. International Journal of Production Research, 54(24), 7523-7545. Doi: 10.1080/00207543.2016.1201606.

Laureani, A., \& Antony, J. (2017). Leadership characteristics for lean six sigma. Total Quality Management \& Business Excellence, 28(3-4), 405-426. Doi: 10.1080/14783363.2015.1090291.

Negrão, L. L. L., Godinho Filho, M., \& Marodin, G. (2017). Lean practices and their effect on performance: a literature review. Production Planning \& Control, 28(1), 33-56. Doi: 10.1080/09537287.2016.1231853.

Pavnaskar, S. J., Gershenson, J. K., \& Jambekar, A. B. (2003). Classification scheme for lean manufacturing tools. International Journal of Production Research,41(13), 3075-3090. Doi: $10.1080 / 0020754021000049817$.

Qureshi, M. I., Rasli, A. M., Jusoh, A., Kowang, T. O., \& Bahru, U. J. (2015). Sustainability: A new manufacturing paradigm. Journal Teknologi, 77(22), 47-53.

Randhawa, J. S., \& Ahuja, I. S. (2017). 5S-a quality improvement tool for sustainable performance: literature review and directions. International Journal of Quality \& Reliability Management, 34(3), 334-361.Doi: 10.1108/IJQRM-03-2015-0045.

Siasos, G. I., Skondras, G. I., Gkanas, E., Hrissagis, K., \& Makridis, S. S. (2017). The Benefits of Lean through an Analysis and Improvement of an Existing Production Line. Mater. Sci. Eng. Adv. Res, 2(1), 15-24.

Tagge, E. P., Thirumoorthi, A. S., Lenart, J., Garberoglio, C., \& Mitchell, K. W. (2017). Improving operating room efficiency in academic children's hospital using Lean Six Sigma methodology. Journal of pediatric surgery, 52(6), 1040-1044. Doi: 10.1016/j.jpedsurg.2017.03.035.

Taj, S., \& Morosan, C. (2011). The impact of lean operations on the Chinese manufacturing performance. Journal of manufacturing technology management,22(2), 223-240.Doi: $10.1108 / 17410381111102234$.

Taj, S. (2008). Lean manufacturing performance in China: assessment of 65 manufacturing plants. Journal of Manufacturing Technology Management, 19(2), 217-234.

Thanki, S., Govindan, K., \& Thakkar, J. (2016). An investigation on lean-green implementation practices in Indian SMEs using analytical hierarchy process (AHP) approach. Journal of Cleaner Production, 135, 284-298. Doi: 10.1016/j.jclepro.2016.06.105 